\title{
Endovasküler Akut İskemik İnme Tedavisi: İlk 100 Vakanın Analizi
}

\section{Endovascular Acute Ischemic Stroke Treatment: Analysis of the First 100 Cases}

\author{
Özcan KOCATÜRK 1 (D), Mehtap KOCATÜRK ${ }^{2}$ (D) \\ ${ }^{1}$ Balıkesir Atatürk Şehir Hastanesi, Nöroloji Anabilim Dalı, Balıkesir, TÜRKiYE \\ 2 Balıkesir Üniversitesi Tıp Fakültesi, Nöroloji Anabilim Dalı, Balıkesir, TÜRKiYE
}

öz.

Amaç: İnme, Türkiye'de tüm ölümlerin \%15'inin nedenidir. Akut iskemik inmede (Aii) tıkanan damarın açılmadığı her dakikada nöron harabiyeti devam etmektedir. Bugün için Aii'nin erken dönem en önemli tedavisi tıkalı damarın hızı ve etkili şekilde açılmasıdır. Bu çalışmada, merkezimizdeki Ail hastalarına uygulanan endovasküler tedavi deneyimlerimizi paylaşmayı amaçladık.

Materyal ve Metod: Ocak 2015 ve Kasım 2018 tarihleri arasında Ail tanısı ile başvuran ve endovasküler tedavi alan ardışık ilk 100 hasta çalışmaya dahil edildi. Tüm hastaların klinik ve demografik özellikleri ile endovasküler işlem özelliklerini kaydettik.

Bulgular: Çalışmaya dahil edilen 100 hastanın 49'u kadın, 51'i erkekti ve yaş ortancası 65 (55-74) idi. Hastaların $\% 74$ 'ünde hipertansiyon, $\% 25^{\prime}$ inde hiperlipidemi, $\% 38^{\prime}$ inde diyabetes mellitus, $\% 26$ 'sınde atrial fibrilasyon, \%36'sında koroner arter hastalığı ve \%39'unda sigara kullanımı mevcuttu. Hastaların tedavi öncesi National Institutes of Health Stroke Scale (NIHSS) skoru 15,5 (13-19) idi. Üç aylık takipte 31 hasta kaybedildi ve mortalite oranı \%31 olarak hesaplandı. Üçüncü ay sonunda $\% 40$ hastada iyi sonuç gözlemlendi (modifiye Rankin skalası skoru 0-2). Etkili rekanalizasyon oranımızın (Thrombolysis in Cerebral Infarction [TICl2b-3]) \%75 olduğu görüldü.

Sonuç: Büyük arter tıkanıklığı düşünülen Aii hastalarının endovasküler tedavi imkanlarının olduğu merkezlere sevki en erken dönemde sağlanmalıdır. Endovasküler tedavi deneyimi artıkça daha iyi sonuçlar elde edilebilir.

Anahtar kelimeler: Akut iskemik inme, Endovasküler tedavi, Mortalite

Abstract

Background: Stroke account for $15 \%$ of all deaths in Turkey. In acute ischemic stroke (AIS), neuronal damage continues every minute until the occluded vessel is not opened. Currently, the most important treatment of AIS is the rapid and effective opening of the occluded vessel. In this study, we aimed to share our experience of endovascular treatment of AIS patients in our center.

Materials and Methods: Between January 2015 - November 2018, the first 100 consecutive patients who presented with the diagnosis of AIS and received endovascular treatment were included in this study. We recorded the clinical and demographic characteristics and endovascular procedure characteristics of al patients.

Results: Of the 100 patients included in the study, 49 were female and 51 were male, and the median age was 65 (55-74). Hypertension was present in $74 \%$, hyperlipidemia in $25 \%$, diabetes mellitus in $38 \%$, atrial fibrillation in $26 \%$, coronary artery disease in $36 \%$, and smoking in $39 \%$ patients. The Median NIHSS score was 15.5 (13-19) prior to treatment. At the 3-month follow-up, 31 patients died and the mortality rate was calculated as $31 \%$. At the end of the 3 -month, good outcome was observed in $40 \%$ of patients (modified Rankin scale score 0 -2). Our effective recanalization rate (Thrombolysis in Cerebral Infarction [TICl2b-3]) was found to be $75 \%$.

Conclusions: AIS patients with suspected large artery occlusion should be transferred to centers where endovascular treatment is available, as soon as possible. Better results can be achieved as experience of endovascular treatment in centers increases.

Key Words: Acute ischemic stroke, Endovascular stroke treatment, Mortality

Sorumlu Yazar / Corresponding Author

Dr. Özcan KOCATÜRK

Gaziosmanpaşa, 209. Sk. No:26, 10100

Altıeylül/Balıkesir, TÜRKiYE

E-mail: ozcankocaturk@gmail.com

Received / Geliş Tarihi: 30.09.2020

Accepted / Kabul Tarihi: 07.02.2021

DOI: $10.35440 /$ hutfd. 803058 


\section{Giriş}

İnme, ciddi bir ölüm ve özürlülük nedenidir. Dünyada her yıl 17 milyonun üzerinde hasta inme geçirmekte ve $6 \mathrm{mi}$ Iyon kişi inme nedeniyle hayatını kaybetmektedir (1). Türkiye de her yıl yaklaşı 132.000 kişi bu hastalığa yakalanmaktadır (2). İnme en sık (\%87) beyin damarlarının tıkanması şeklinde oluşur. Tıkalı beyin damarının tekrar açılması ile serebral kan akımının zamanında restorasyonu, enfarkt olmayan iskemik beyin dokusunun kurtarılması için en etkili yöntemdir. Akut iskemik inme (Aii) geçiren uygun hastalar için intravenöz alteplaz (rekombinant doku plazminojen aktivatörü), semptomların başlamasından sonra 4.5 saat içinde başlanması koşuluyla birinci basamak tedavidir (3). Intravenöz alteplaz tedavisi etkili ve kolay ulaşılabilen bir tedavi olmasına rağmen ülkemizde inme semptomlarının farkındalığının az olması nedeniyle hastalar acil servise geç başvurdukları için bu tedaviden yeterince faydalanamamaktadırlar. Ayrıca intravenöz alteplaz tedavisinin birçok kontraendikasyonu da bulunmaktadır (3). Endovasküler tedavi seçenekleri bu durumlarda ön plana çıkmaktadır.

Mekanik trombektomi, büyük arter tıkanması nedeniyle Ail geçiren hastalar için önerilmekte ve semptom başlamasından sonra 24 saat içinde uygun hastalar tedavi edilebilmektedir (4). Mekanik trombektomi tedavisi, anjiografi laboratuarında beyin damarını tıkayan trombusun mekanik yollar ile uzaklaştırılmasına dayanır. Mekanik trombektomi için geri-çekilebilen stentler (stent-retriver) ve/veya kateter aspirasyon cihazları kullanılabilir. Bazı durumlarda, stent-retriverlar ve aspirasyon teknikleri beraber kullanılarak tedavi uygulanabilir.

2015 yılında yapılan beş büyük çok merkezli çalışmanın dahil edildiği meta analizde (Highly Effective Reperfusion evaluated in Multiple Endovascular Stroke Trials, HERMES) iskemik inme hastalarında mekanik trombektominin güvenli ve etkili olduğu bildirilmiş ve stantdart intravenöz fibrinolitik tedaviden üstün olduğu ortaya konulmuştur (5). Bu çalışmalarda bir hastanın fonksiyonel bağımsızlığını kazanması için tedavi edilmesi gereken hasta sayısının ortalama 3-7,5 arasında olduğu bildirilmiştir (5).

Biz bu çalışmada endovasküler inme tedavisi uyguladığımız ilk 100 ardışık hastanın analizini yapıp sonuçları paylaşmayı amaçladık.

\section{Materyal ve Metod}

Merkezimizde tüm mekanik trombektomi tedavisi uygulanan iskemik hastalar için bir veri tabanı tutulmaktadır. Bu veri tabanı retrospektif olarak incelendi. Ocak 2015 ile Aralık 2018 tarihleri arasında, mekanik trombektomi tedavisine başlanılan toplam 100 hastanın verisi geriye dönük olarak gözden geçirildi. Bu dönemde trombektomi yapılan tüm hastalar çalışmaya dahil edildi. Hastaların demografik özellikleri, risk faktörleri ve iskemik inme tedavisi ile alakalı zaman parametreleri (semptom-kapı, kapı-kasık giriş, kasık giriş-revaskülarizasyon zamanı) kayıt edildi. Hastaların inme etiyolojileri ve National Instutute of
Health Stroke Scale (NIHSS) puanları (0 ve 24 saat sonra) değerlendirildi. Hastalar işleme alınmadan önce beyin bilgisayarlı tomografi (BT) değerlendirildi ve ASPECT (AIberta Stroke Program Early CT Score) değerleri hesaplandı. Modifiye Rankin ölçeği (mRS) inme sonrası 90. Günde kayıt edildi. Hastalardan veya yakınlarından tedaviden önce bilgilendirilmiş onam alındı. Bu çalışma Harran üniversitesi yerel etik komitesi tarafından onaylandı( Evrak Tarih ve Sayısı: 28/08/2019-E.35556).



Şekil 1-a. Orta serebral arteri tıkanan bir olgunun işlem öncesi anjiog rafik görünümü

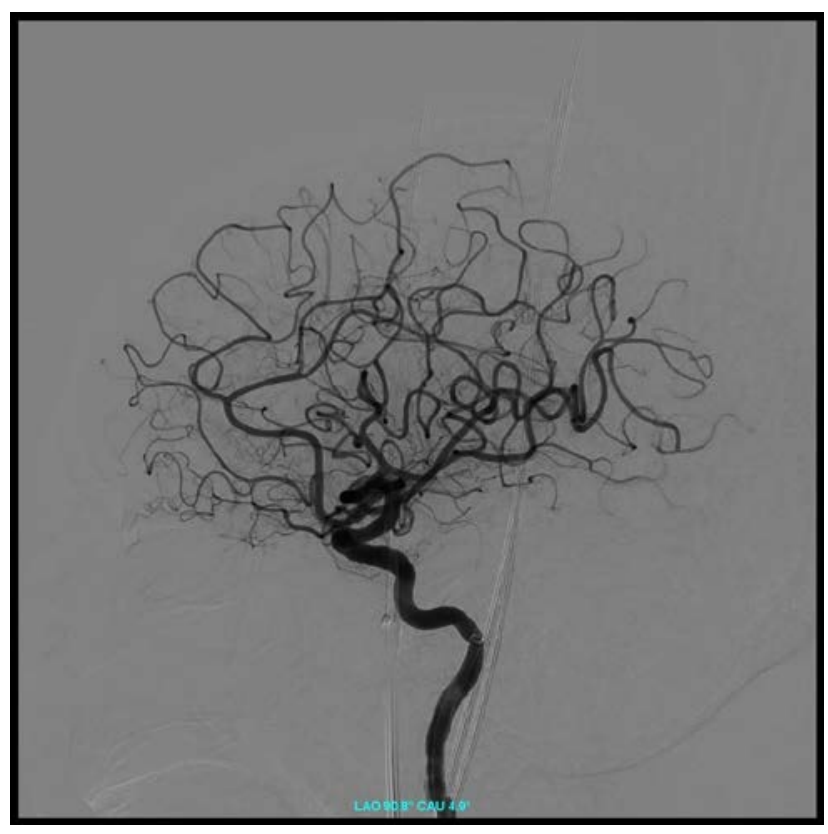

Şekil 1-b. Orta serebral arteri tıkanan hastanın endovasküler müdahale sonrası başarılı rekanalizasyon 
Acil servise inme semptoları ile başvuran veya başka bir merkezde değerlendirilip endovasküler tedavi için merkezimize gönderilen tüm hastalar bilgisayarlı tomografi (BT) (Beyin BT, Boyun-Beyin BT angiografi) veya Manyetik rezonans görüntüleme (MRG) (Beyin MRG, Boyun-Beyin MRG angiografi) yöntemi ile değerlendirildi. Büyük damar tıkanıklığı saptanan ve semptom başlamasından sonra ilk 8 saat içinde başvurabilen hastalara endovasküler tedavi uygulandı. Tedavi sonrası serebral hemoraji geçiren hastaları sınıflandırmak için European Cooperative acute stroke study (ECASS-2) kullanıldı (6). İşlem sonrası elde edilen revaskülarizasyon için modified Thrombolysis in Cerebral Infarction ( $\mathrm{mTICl}$ ) skorlaması kullanıldı (7). Üç aylık Modifiye Rankin ölçeği (mRS) skorları hastalar değerlendirilerek veya telefon görüşmeleri yoluyla hesaplandı. Üçüncü ayındaki mRS'si 0-2 olarak değrelendirilen hastalar iyi sonuç almış kabul edilirken, mRS skoru 3-6 arası kötü sonuç olarak kabul edildi(89).Verileri analiz etmek için SPSS versiyon 20.0 kullanıldı. Merkezimizde endovasküler ıskemik inme tedavisi alan bir hastanın işlem öncesi ve sonrası anjiografisi Şekil-1 de gösterilmektedir Sürekli veriler median ve interquartil range (IQR; 25 ve 75) olarak, kategorik veriler ise sayı ve yüzde olarak ifade edildi.

\section{Bulgular}

Çalışmaya dahil edilen hastaların ortanca yaşı 65 (54-75) idi. 49 hasta kadın cinsiyetinde, 51 hasta erkek idi. Hastaların \%74'ünde hipertansiyon, \%25'inde hiperlipidemi, \%38'inde diyabetes mellitus, $\% 26$ 'sınde atrial fibrilasyon, \%36'sında koroner arter hastalığı ve \%39'unda sigara kullanımı mevcuttu.

İnme şiddetini belirlemek için kullandığımız NIHSS değeri, hastaneye başvuru anında 15,5 (13-19) olarak hesaplandı. ASPECT skoru 7 (6-9) olarak hesaplandı. Hastalarımızın semptom başlamasından acil servise geliş süresi (semptom-kapı) 185 (126-309) dakika, acil servisten anjiyografi ünitesine alınıp ponksiyon yapılma süresi (kapı-ponksiyon) 42 (30-62) dakika, ponksiyondan hedef damarın açılmasına kadar geçen süre ise (Ponksiyon-Revaskülarizasyon) 44 (29-75) dakika olarak hesaplandı. Hastalarımızın \%13' ü uyanma inmesi olarak değerlendirildi. Hastaların \%25'i endovasküler tedavi öncesi intravenöz trombolitik tedavi almışlardı (Tablo 1).

Hastaların angiografik verilerine baktığımız zaman; tıkanan damar lokalizasyonu \%46'sında orta serebral arter proksimal kısmı (MCA, M1), \%7 'sinde orta serebral arter distal kısmı (MCA M2), \%21'ünde intrakranial internal karotid arter (ICA-Intracranial), \%20'sinde ekstrakranial internal karotid arter ve orta serebral arter beraber tıkanıklıgı (ICA-Tandem) ve \%6 'sında da vertebrobaziler sistemde tıkanıklık şeklinde bulundu. Endovasküler işlem esnasında internal karotid arterdeki antegrad akımı kesmek için kullanılan balon kılavuz kulanım oranımız \%20 (20) olduğu görülmüştür. Illk geçiş (First pass) rekanalizasyon \%25 hastada elde edildi. Endovasküler işlem esnasında 24 (\%24) hastamızda kalıcı stent implate edilmiştir. Bu kalıcı stentlerin 18 (\%75) tanesi ekstrakraniyel internal karotid artere, 4 (\%17) tanesi MCA M1 bölgesine, 1 (\%4) tanesi baziler artere, 1 (\%4) taneside eksrakraniyel vertebral artere konulmuştur. Tıkalı hedef arteri açmak için intrakranial yaptığımız toplam işlem sayımızın ortanca değerinin 2.8 (1.3-4) olduğu görülmüştir (Tablo 2).

Tablo1. Hastaların bazal demografik ve klinik verileri

\begin{tabular}{|c|c|}
\hline Toplam Hasta Sayısı (n) & 100 \\
\hline Yaş (yıl) & $65(55-74)$ \\
\hline \multicolumn{2}{|l|}{ Cinsiyet } \\
\hline Kadın, (\%) & 49 (49) \\
\hline Erkek, (\%) & $51(51)$ \\
\hline İnme ciddiyeti, Bazal NIHSS & $15,5(13-19)$ \\
\hline Hipertansiyon, (\%) & $74(74)$ \\
\hline Hiperlipidemi, (\%) & $25(25)$ \\
\hline Atrial fibrillasyon, (\%) & $26(26)$ \\
\hline Koroner arter hastalı̆ı̆ı, (\%) & $36(36)$ \\
\hline Diyabet, (\%) & $38(38)$ \\
\hline Sigara, (\%) & $39(39)$ \\
\hline Bazal kan glukozu, mg/dl & $130(105-170)$ \\
\hline ASPECT & $7(6-9)$ \\
\hline \multicolumn{2}{|l|}{ Etiyoloji, (\%) } \\
\hline Kardiyoemboli & 39(39) \\
\hline Büyük damar aterosklerozu & $29(29)$ \\
\hline Kriptojenik & $32(32)$ \\
\hline \multicolumn{2}{|l|}{ Zaman Parametreleri (dakika) } \\
\hline Semptom-kapı ${ }^{\#}$ & $185(126-309)$ \\
\hline Kapı-femoral ponksiyon & $42(30-62)$ \\
\hline Femoral ponksiyon-revaskülarizasyon ${ }^{*}$ & $44(29-75)$ \\
\hline Uyanma inmesi, (\%) & $13(13)$ \\
\hline İntravenöz trobolitik, (\%) & $25(25)$ \\
\hline \multicolumn{2}{|l|}{ mRS (90. Günde) ,(\%) } \\
\hline $0-2$ & $40(40)$ \\
\hline 3-5 & $29(29)$ \\
\hline 6 (mortalite) & $31(31)$ \\
\hline \multicolumn{2}{|l|}{ Anestezi türü, (\%) } \\
\hline Genel & $4(4)$ \\
\hline Sedasyon & $96(96)$ \\
\hline
\end{tabular}

*75 Hastada belirlendi, \# 87 hastada belirlendi.

ASPECT:Alberta Stroke Program Early CT Score, mTICl: modified Thrombolysis in Cerebral Infarction, Semptom-Kapı: Semptom başlama süreli ile hastane aciline gelene kadar süre, Kapı-Ponksiyon:Hastaneye geldikten sonra anjiografinin başlamaya kadar geçen süre

Ponksiyon-Revaskülarizasyon: Anjiografi başladıktan sonra damar açılana kadar geçen süre

NIHSS: National Institutes of Health Stroke Scale,

mRS: modified Rankin scale

Komplikasyonlarımıza baktığımızda 11 (\%11) hastamızda semptomatik kanama, 3(\%3) hastamızda intra-operatif damar rüptürü, 2 (\%2) hastamızda kan akım geçişini belirgin azaltan disseksiyon saptandı. 9(\%9) hastamızda işlem başladığında tamamen normal olan arter sahasına işlem esnasında emboli (yeni arter alanına embolizasyon) olduğu görüldü. 90 gün takipte $31(\% 31)$ hastamızda mortalite saptandı

3 aylık takip sonucunda 40 (\%40) hastamızda iyi sonuç (mRS 0-2) elde edilirken, kötü sonuç (mRS 3-6) 60 (\%60) hastamızda gözlendi. 
Tablo 2. Dijital subtraksiyon anjiyografi (DSA) bulguları ve teknik özellikler

\begin{tabular}{|c|l|}
\hline Tıkanıklık yeri, (\%) & $46(46)$ \\
MCA-M1 & $7(7)$ \\
MCA-M2 & $21(21)$ \\
ICA-Intrakranial & $20(20)$ \\
ICA-Tandem & $6(6)$ \\
Vertebro-Basiler & $75(75)$ \\
\hline Başarılı reperfüzyon (TıCI 2b-3), (\%) & \\
\hline Komlikasyon, (\%) & $3(3)$ \\
Intaoperatif damar ruptürü & $11(11)$ \\
Semptomatik kanama & $2(1)$ \\
Disseksiyon & $9(9)$ \\
Yeni arter alanına emboli & \\
Stent retriever trombektomi & $42(42)$ \\
Trombo-aspiration(ADAPT) & $40(40)$ \\
Primer Kombine yaklaşım & $18(18)$ \\
\hline Illk basamak endovasküler yöntemi & $20(\% 20)$ \\
\hline Balonlu Klavuz kateter kullanımı,n(\%) & $2.81(1.25-4)$ \\
\hline İntrakranial toplam islem sayısı & $25(\% 25)$ \\
\hline İlk geçiş rekanalizasyon n(\%) & $24(\% 24)$ \\
\hline İşlem esnasında kalıcı stent, n(\%) & \\
MCA: Orta serebral arter & \\
ICA : Inetrnal karotid arter & \\
Tandem:orta serebral arter ve internal karotid arter beraber tıkanıklığı \\
ADAPT: A direct aspiration first-pass technique \\
\hline
\end{tabular}

Tablo 3. Bu çalışmanın verileri ile HERMES analizini verilerinin kıyaslanması.

\begin{tabular}{llll}
\hline & Bu Çalışma & \multicolumn{2}{c}{ Hermes Analizi (3) } \\
\hline & & $\begin{array}{l}\text { Trombektomi } \\
\text { Grubu }\end{array}$ & $\begin{array}{l}\text { Kontrol } \\
\text { Grubu }\end{array}$ \\
\hline Hasta sayısı & 100 & 634 & 653 \\
Yaş & $65(55-74)$ & $68(57-77)$ & $68(59-76)$ \\
$\begin{array}{l}\text { Bazal NIHSS } \\
\text { ASPECT }\end{array}$ & $15,5(13-19)$ & $17(14-20)$ & $17(13-21)$ \\
$\begin{array}{l}\text { Intravenöz trombo- } \\
\text { litik }\end{array}$ & $7(6-9)$ & $9(7-10)$ & $9(8-10)$ \\
Semptom & & $\% 83$ & $\% 87$ \\
başlangından damar & $303(235-416)^{*}$ & $285(210-360)$ & Veri yok \\
$\begin{array}{l}\text { açılana kadar sure, } \\
\text { dakika }\end{array}$ & & & \\
$\begin{array}{l}\text { Başarılı reperfüzyon } \\
\text { (TICI 2b-3) }\end{array}$ & $\% 75$ & & \\
mRS 0-2, 90. gün & $\% 40$ & $\% 71$ & Veri yok \\
Mortalite & $31(\% 31)$ & $\% 15 \cdot 3$ & $\% 18 \cdot 5$ \\
\hline
\end{tabular}

*64 hastada belirlendi

ASPECT:Alberta Stroke Program Early CT Score, mTICl: modified Thrombolysis in Cerebral Infarction, NIHSS: National Institutes of Health Stroke Scale, mRS: modified Rankin scale, HERMES: Highly Effective Reperfusion evaluated in Multiple Endovascular Stroke Trials

\section{Tartışma}

Merkezimizde endovasküler iskemik inme tedavisini başlatığımız Ocak 2015 tarihinden sonraki ardışık ilk 100 hastamızın analizini yaptığımızda 90 günde iyi sonuç oranımızı (mRS 0-2) \%40 olarak bulduk. 2015 yılında yayınlanan ve sonrasında endovasküler tedavinin inme klavuzlarına girmesini sağlayan 5 randomize klinik çalışmanın meta analizinde (HERMES) 90. günde iyi sonuç \%46 olarak bildirilmiştir (5). Yine bu analizde kontrol grubunda iyi sonuç \%26 olarak bildirilmiştir. Bizim sonuçlarımız ile kıyaslandığında ise girişim yapılan gruba göre düşük çıkarken kontrol grubuna göre yüksek bulunmuştur. Trombektomi yapılan iskemik inme hastlarında iyi sonuçlanmayı etkileyen faktörler arasında yaş, inme şiddeti (Basal NIHSS), ASPECT skoru ve anjiyografik sonuç (mTICl:3) sayılabilir. Bizim çalışmamız HERMES analizi ile kıyaslandığında yaş ve NIHSS bakımından hafif düşük olmakla birlikte ASPECT skoru bizim çalışmamızda daha düşüktür (Tablo 3). Bu durum göz önüne alındığında bizim hasta populasyonumuzun işlem öncesi sahip olduğu enfarkta uğramış doku miktarının daha fazla olduğu anlamına gelebilir. Bizim çalışmamızda iyi sonucun bir miktar düşük olmasının nedenlerinden biri; çalışma populasyonumuzun ASPECT skorlarının düşük olması olabilir.

Üçüncü aydaki mortalite oranımız \%31 olarak bulduk. Hermes analizinda girişim yapılan grupta mortalitenin \%15 olduğu düşünüldüğünde bizim mortalite oranımız yüksektir. Bu durum gerek endovasküler işlemin getirdiği riskler gerekse de işlem sonrası yoğun bakım süreçleri ile alakalı olabilir. Ancak Hermes çalışması klinik çalışmaların sonucunu derlediği için gerçek yaşam verileri ile her zaman uyuşmayabilir. Trombektomi sonrası mortaliteyi araştıran bir çalışmada gerçek yaşam verilerinin klinik çalışmalarda çıkan sonuçlara göre daha yüksek bulunmuştur(10).

Bizim çalışma grubumuzda işlem öncesi intravenöz tedavi uygulanması \%25 oranında bulunmuştur. Bu durum literatür ile kıyaslandıgında belirgin düşüktür (5). Semptom kapı süremizin 185 dakika (126-309) olduğu düşünüldüğünde intravenöz tedavi oranımızın daha yüksek olması beklenebilir. Bu düşüklüğün muhtemel nedeni merkez olarak endovasküler tedaviye odaklanıldığı için intravenöz tedaviye gereken önemin verilememesi olabilir. Tedavi ekibi, etkinliği daha fazla olan tedavi modalitesine meyil edebilmektedir. Yapılan çalışmalarda intravenöz alteplaz kullanımının uygun hasta populasyonunda faydalı olduğu gösterilmiştir (11). Ancak özellikle proksimal büyük damar tıkanıklığında faydası belirgin derecede azalmaktadır (12). Ayrıca endovasküler tedavi olanaklarının bulunduğu bir ortamda intravenöz trombolitiğin hastaya ek fayda sağlayıp sağlayamadığı da şüphelidir (13). İntravenöz trombolitik tedavi; endovasküler tedaviyi geciktirmesinin yanında, ulaşılması kolay olan proksimal oklüzyonu fragmente edip ulaşılması zor distal tıkanıklıklar haline getirdiği için hastaya zarar verdiği düşünülmektedir. 2018 yılında bu konu ile ilgili yayınlanan bir meta analizde, öncesinde trombolitik yapılıp yapılmamasının hasta sonuçlarını çok etkilemediği bildirilmiştir (14). Hastanemizde bu konu ile ilgili daha net kanıtlar elde edilene kadar şu an için intravenöz tedavi uygulanması desteklenmektedir.

Endovasküler tedaviler genel anestezi altında veya sedasyon anestezisi ile gerçekleştirilebilmektedir. Genel anestezi, hasta ve hekim konforu açısından iyi olmasının yanında olası damar yaralanmaları (disseksiyon ve ruptür) riskini de azaltmaktadır. Buna karşın anestezi sağlanana kadar geçen süre kaybı ve anestezik ajanların tetiklediği hipotansiyon iyi sonuç oranını azaltabilmektedir. Sedasyon anestezisinde hasta hareketi tam engellenemediği için hekimin konforunu bozmakla birlikte zaman kaybını azalttığı ve hipotansiyon riski taşımadığı için hasta iyi sonuçlanmasına etkisi olumludur. Mekanik trombektomi sonrası hasta eğer entübe alınmış ise ekstübasyonuda zor olmaktadır. Şu anki veriler ışığında iki 
anestezi türünün birbirlerine üstünlüğü gösterilememiştir (15). Bizim hastanemizde hastalarımızın büyük çoğunluğu sedasyon altında işleme alınmaktadır (\%96). Ancak tecrübemizin artıp daha küçük damarlardaki trombüslere müdahale oranlarımız arttıkça (distal trombektomi) genel anesteziye olan ihtiyacımızın da artması beklenmektedir. Balonlu klavuz kateterlerin (baloon guide catheter) internal karotid arterde antegrad akımı keserek distal embolizasyonu azalttığı ve rekanalizasyon oranını arttırdığ sonuç olarak daha iyi klinik sonuçlanma ile ilişkili olduğu gösterilmiştir (16). Bu nedenle Güncel kılavuzlar balonlu kılavuz kateterin kullanılmasını önermektedir (17). Bizim çalışma grubumuzda balonlu kılavuz kateter kullanım oranı \%20 olduğu görülmüştür. Bu oranın beklenenden düşük olması ülkemizde bu tip kateterlerin kolayca ulaşılabilir olmaması ve bu kateterlerin kullanımının tecrübe gerektirmesi olabilir.

Hızlı ve tam rekanalizasyon mekanik trombektomi tedavisinin iyi sonuçlarını artırmaktadır. Tek bir kez intrakranial girişimden sonra efektif rekanalizasyon (mTICl2b-3) oluşması ilk geçiş etkisi (IGE) olarak adlandırılmıştır. IGE'nin, artmış klinik faydalanma ve azalmış mortalite ile ilişkili olduğu ve artmış intrakranial girişim sayısının tam tersi etkiye sahip olduğu bildirilmiştir (18). Bizim çalışma grubumuzda IGE \%25 ve ortalama intrakranial pass sayısı 2.8 (1.3-4) olarak bildirilmiştir olup bu oran literatür ile uyumludur(19). Yine mortaliteyi etkileyen bir diğer angiografik parametre başarılı rekanalizasyondur. Biz çalışmamızda rekanalizasyon oranlarını belirlemek için modified Thrombolysis in Cerebral Infarction ( $\mathrm{mTICl}$ ) skorlamasını kullandık (7). Bu skorlamaya göre mTICl2b-3 skoru başarılı rekanalizasyonu göstermektedir. Bizim çalışmamızda mTICl2b-3 oranı \%75 olduğu görülmüştür. Akut iskemik inmenin endovasküler tedavisinde erken dönemde yüksek doz anti-agregan kullanımı gerektirdiği için kalıcı stent kullanımı önerilmemektedir. Kalıcı stent kullanılan hastalarda mortalite ve semptomatik kanamanın artırdığı gösterilmiştir (20). Ancak bazı durumlarda akut stent kullanımı uygun reperfüzyon sağlamak için gerekebilmektedir. Akut stentleme, bazen alınamayan trombusu damar duvarına hapsetmek için bazen de ikili (tandem) oklüzyonlarda internal karotid arterin proksimalindeki atherosklerotik plağın tedavisi için kulanılmaktadır. Bizim çalışma grubumuzda \%24 oranında akut stentleme yapılmıştır.

Mekanik trombektomi konusunda bugün için hala tartışmalı konulardan birisi de trombektomi yöntemidir. Temel olarak iki yöntem mevcuttur. Geri çekilebilir stentlere dayanan stent retriver trombektomi ve geniş kateterler ile yapılan trombo-aspirasyon (ADAPT- A direct aspiration first-pass technique) yöntemidir. İki yöntem ile yapılan kıyaslamalı çalışmalarda bu iki yöntimin birbirlerine üstün olmadıkları gösterilmiştir (21). Bu iki yöntemin beraber kullanılması ile oluşan primer kombine yöntem son zamanlarda popülerlik kazanmaktadır. Bizim çalışma grubumuzda bu yöntemler denenmiştir (Tablo 2). Hastanemizde son bir yıldır primer kombine yöntem ağırlıklı olarak kullanılmaktadır.

Çalışmanın kısıtlılıkları, tek merkez olması, geriye dönük bir çalışma olması, kontrol grubunun olmaması, revaskülarizasyon tekniklerimizin çeşitlilik göstermesi ve erken dönem vakalarının verilerinin güvenilir olmaması şeklinde sayılabilir

Sonuç olarak Ail hastalarında serebral kan akımının olabilecek en erken zamanda tekrar sağlanması çok önemlidir. Bugünkü kılavuzlar eşliğinde intravenöz trombolitik uygun hastalarda ilk tercih edilen tedavi yöntemi olmalıdır. Büyük arter tıkanıklığı düşünülen hastalar en erken dönemde endovasküler tedavi imkanlarının olduğu merkezlere sevk edilmelidir. Merkezlerde endovasküler tedavi deneyimi artıkça daha iyi sonuçlar elde edilebilmektedir.

Etik onam: Bu çalışma harran üniversitesi tıp fakültesi girişimsel olmayan klinik araştırmalar etik kurulu tarafından onaylanmıştır.( Evrak Tarih ve Sayısı: 28/08/2019-E.35556).

Yazar Katkıları:

Konsept: Ö.K.

Literatür Tarama: M.K.

Tasarım: Ö.K.

Veri toplama: M.K.

Veri analizi ve yorumlama: Ö.K.

Makale yazımı: Ö.K.

içeriğin eleştirel incelenmesi: M.K.

Çıkar Çatışması: Yazarlar herhangi bir çıkar çatışması olmadığını beyan eder.

Finansal Destek: Bu çalışma için herhangi bir kaynaktan maddi destek alınmamıştır

\section{Kaynaklar}

1. LB. Goldstein. Ischemic cerebrovascular Disease, In: L. Goldman, A.I. Schafer(Eds) Goldman- Cecil Medicine 25th edition Elsevier Saunders, USA 2016, pp 2434-45.

2. Özkan E, Arsava EM, Topçuoğlu MA, Akut Inme ; Hasta değerlendirilmesi. Gökçe $M$, editör.Inme-1 Ankara: Türkiye Klinikleri; 2018 p.20-6

3. Silva GS, Nogueira RG. Endovascular Treatment of Acute Ischemic Stroke. Continuum (Minneap Minn). 2020;26(2):310-331.

4. Nogueira RG, Jadhav AP, Haussen DC, Bonafe A, Budzik RF, Bhuva P,et al.; DAWN Trial Investigators. Thrombectomy 6 to 24 Hours after Stroke with a Mismatch between Deficit and Infarct. N Engl J Med. 2018 Jan 4;378(1):11-21.

5. Goyal M, Menon BK, van Zwam WH, Dippel DW, Mitchell PJ, Demchuk AM, et al. HERMES collaborators. Endovascular thrombectomy after large-vessel ischaemic stroke: a meta-analysis of individual patient data from five randomised trials. Lancet. 2016 Apr 23;387(10029):1723-31.

6. Hacke W, Kaste M, Fieschi C, von Kummer R, Davalos A, Meier D, et al. Randomised double-blind placebo-controlled trial of thrombolytic therapy with intravenous alteplase in acute ischaemic stroke (ECASS II). Second European-Australasian Acute Stroke Study Investigators. Lancet. 1998 Oct 17;352(9136):1245-51 
7. Zaidat OO, Yoo AJ, Khatri P, Tomsick TA, von Kummer R, Saver JL, et al. Recommendations on Angiographic Revascularization Grading Standards for Acute Ischemic Stroke: A Consensus Statement. Stroke; a journal of cerebral circulation 2013;44:2650-63.

8. Banks JL, Marotta CA. Outcomes validity and reliability of the modified Rankin scale: implications for stroke clinical trials: a literature review and synthesis. Stroke. 2007 Mar;38(3):1091-6.

9. Chen CJ, Ding D, Starke RM, Mehndiratta P, Crowley RW, Liu KC, et al. Endovascular vs medical management of acute ischemic stroke. Neurology. 2015 Dec 1;85(22):1980-90.

10. Qureshi Al, Singh B, Huang W, Du Z, Lobanova I, Liaqat J,et al. Mechanical Thrombectomy in Acute Ischemic Stroke Patients Performed Within and Outside Clinical Trials in the United States. Neurosurgery. 2020 Jan 1;86(1):E2-E8.

11. Hacke $W$, Kaste $M$, Bluhmki $E$, Brozman $M$, Dávalos $A$, Guidetti $D$, et al. Thrombolysis with alteplase to 4.5 hours after acute ischemic stroke. N Engl J Med 2008;359: 131729

12. De Silva DA, Brekenfeld C, Ebinger M, Christensen S, Barber PA, Butcher KS, et al. The benefits of intravenous thrombolysis related to the site of baseline arterial occlusion in the Echoplanar Imaging Thrombolytic Evaluation Trial (EPITHET). Stroke 2010; 41: 295-99.

13. Fischer U, Kaesmacher J, Mendes Pereira V, Chapot R, Siddiqui $A H$, Froehler MT, et al. Direct mechanical thrombectomy versus combined intravenous and mechanical thrombectomy in large-artery anterior circulation stroke: a topical review. Stroke 2017;48:2912-8.

14. Kaesmacher J, Mordasini P, Arnold M, López-Cancio E, Cerdá N, Boeckh-Behrens $\mathrm{T}$, et al. Direct mechanical thrombectomy in tPA-ineligible and -eligible patients versus the bridging approach: a meta-analysis. J Neurointerv Surg 2019 Jan;11:20-27.

15. Simonsen CZ, Yoo AJ, Sørensen LH, Juul N, Johnsen SP, Andersen $\mathrm{G}$, et al Effect of General Anesthesia and Conscious Sedation During Endovascular Therapy on Infarct Growth and Clinical Outcomes in Acute Ischemic Stroke: A Randomized Clinical Trial. JAMA Neurol 2018 Apr 1;75:470477.

16. Nguyen TN, Malisch T, Castonguay AC, Gupta R, Sun $\mathrm{CH}$, Martin $\mathrm{CO}$, et al. Balloon guide catheter improves revascularization and clinical outcomes with the solitaire device: analysis of the North american solitaire acute stroke registry. Stroke 2014;45:141-145.

17. Powers WJ, Rabinstein AA, Ackerson T, Adeoye OM, Bambakidis NC, Becker K, et al; American Heart Association Stroke Council. 2018 Guidelines for the early management of patients with acute ischemic stroke: a guideline for healthcare professionals from the American Heart Association/American Stroke Association. Stroke 2018;49:e46e110.

18. Ducroux C, Piotin M, Gory B, Labreuche J, Blanc R, Ben Maacha M, et al; ASTER Trial investigators. First pass effect with contact aspiration and stent retrievers in the Aspiration versus Stent Retriever (ASTER) trial. J Neurointerv Surg 2019 Aug 30. pii: neurintsurg-2019-015215.

19. Zaidat OO, Castonguay AC, Linfante I, Gupta R, Martin CO, Holloway WE, et al . First Pass Effect: A New Measure for Stroke Thrombectomy Devices. Stroke 2018;49:660-666.
20. Samaniego EA, Dabus G, Linfante I. Stenting in the treatment of acute ischemic stroke: literature review. Front Neurol 2011:9;2:76.

21. Hsieh KL, Chuang KI, Weng HH, Cheng SJ, Chiang Y, Chen CY. First-Line A Direct Aspiration First-Pass Technique vs. First-Line Stent Retriever for Acute Ischemic Stroke Therapy: A Meta-Analysis. Front Neurol 2018 Sep 25;9:801. 